\title{
EFFECTS OF STRAW DECOMPOSITION ON AGGREGATE COMPOSITION AND AGGREGATE-ASSOCIATED ORGANIC CARBON IN DIFFERENT SOIL MINERAL TYPES
}

\author{
LIU, Z. $.^{1,2,3,4}-$ SUN, Z. H. ${ }^{1,2,3,4^{*}}-$ WANG, H. Y. $.^{1,2,3,4}-$ CAO, S. L. ${ }^{1}-$ CHEN, T. Q. ${ }^{1,2,3,4}-$ \\ QU, S. D. ${ }^{1,2,3,4}-$ LEI, N. ${ }^{1,2,3,4}-$ DONG, Q. G. ${ }^{1,2,3,4}$ \\ ${ }^{1}$ Shaanxi Provincial Land Engineering Construction Group Co., Ltd., Xi'an 710075, China \\ ${ }^{2}$ Institute of Land Engineering and Technology, Shaanxi Provincial Land Engineering \\ Construction Group Co., Ltd., Xi'an 710075, China \\ ${ }^{3}$ Key Laboratory of Degraded and Unused Land Consolidation Engineering, the Ministry of \\ Natural Resources, Xi'an 710075, China \\ ${ }^{4}$ Shaanxi Provincial Land Consolidation Engineering Technology Research Center, Xi'an \\ 710075, China \\ ${ }^{*}$ Corresponding author \\ e-mail: liuzhe168@126.com; phone: +86-029-8662-5020; fax:+86-029-8662-5020
}

(Received $16^{\text {th }}$ Apr 2020; accepted $11^{\text {th }}$ Aug 2020)

\begin{abstract}
Straw is an important organic resource that could be recycled, however, few studies investigated the effects of straw decomposition on aggregate stability and organic carbon (OC) of different mineral soils. In this study, we conducted a constant temperature incubation experiment for 120 days in three different mineral soils consisting of two treatments: control soil and straw-amended soil. The results showed that straw addition promoted a significant increase of $>2 \mathrm{~mm}$ water-stable macroaggregates as well as a significant decrease of microaggregates $(<0.25 \mathrm{~mm})$ compared with control soils $(P<0.05)$. From day 15 to day 120 , the three straw-amended soils significantly increased in mean weight diameter (MWD) and geometric mean diameter (GMD). The OC concentration of different particle-size aggregates in strawamended soils increased significantly during the early 15 days of incubation, then gradually decreased during the later stages. After 120 days of incubation, the contribution of OC of macroaggregates to soil organic carbon in fluvo-aquic soil reached the highest $(66.14 \%)$. Among them, the fluvo-aquic soil with 2:1 clay mineral showed better improvement of aggregate stability and OC concentration than red soil during straw decomposition. These results confirm the differences and benefits of straw application for soil structure and quality of different clay mineral types.
\end{abstract}

Keywords: straw-amended soil, incubation, water-stable aggregates, aggregate stability, soil organic carbon

\section{Introduction}

Soil aggregate is a special organic-inorganic-biological complex with multi-level structure or fractal characteristics. Its formation and stability process are extremely complex. As the basic unit of soil structure, it features complicated formation and stability process which is not only affected by the material composition of the soil itself, but also by human activities and other factors (Verchot et al., 2011; Zhang et al., 2014; Rabot et al., 2018). Quality soil aggregate plays an important role in regulating soil properties, as well as maintaining soil fertility and ecological environment function. It is not only conducive to the efficient use of water and fertilizer and crop growth, but also to improve soil erosion resistance and carbon sequestration. As its stability is closely related to many soil properties and the ecological environment, it 
plays a vital role in maintaining the sound and sustainable development of soil and the protection of ecological environment (Blanco-Canqui and Lal, 2004; Abiven et al., 2007; Bandyopadhyay and Lal, 2014; Wang et al., 2017). On the contrary, the decrease of soil structure stability will not only reduce the water and fertilizer utilization efficiency of the soil, but it also affects crop yield by increasing the risk of soil degradation and soil erosion, and destroying the sound and sustainable development of soil (Lal, 2008; Li et al., 2017; Vaezi et al., 2017). Therefore, the research on the structural stability and function of soil aggregates has always been one of the main focuses in the field of soil science.

Soil organic carbon (SOC) is the main factor of carbon balance in terrestrial ecosystems, and its small fluctuation may have a significant impact on greenhouse gas emissions and even carbon balance in terrestrial ecosystems (Vanhala et al., 2008; Lu et al., 2013). According to the research, there is a close relationship between SOC and aggregates, and the interaction between the formation of aggregates and the carbon sequestration is of great significance to promote soil carbon sequestration. As the main source of SOC, exogenous new carbon contains a variety of nutrient elements, whose direct addition can increase the number and activity of soil microorganisms, and promote the accumulation of SOC (Fonte et al., 2009; Blaud et al., 2012; HayduHoudeshell et al., 2018). The stability of soil aggregates mostly refers to the water stability of soil aggregates. The content and stability of water-stable aggregates play an important role in evaluating the stability of soil structure and soil anti-erosion ability. SOC is one of the most important factors that affect the structure of soil aggregates. As an important cementing substance in the formation of soil aggregates, it plays an important role in the formation of aggregates with different number and particle size distribution, promoting the aggregation of aggregates and the stability of water-stable aggregates (Chivenge et al., 2011; Ji et al., 2014; Zhu et al., 2017). At the same time, OC can be found mainly in aggregates, and soil aggregation can provide physical protection for SOC. Therefore, relevant scholars regard the stability of soil aggregates or the carbon sequestration capacity of soil as an important index to evaluate soil physical properties and SOC pool. They think that the improvement of the stability of soil aggregates, the quantity and quality of aggregates, as well as the content of SOC pool plays an important role in promoting the sound and sustainable development of agriculture and carbon cycle (Peth et al., 2008; Bimüller et al., 2016).

Straw is an important organic resource that can be recycled, at present, great importance has been attached to the sustainable development of agriculture by adopting the conservation tillage method with straw amendments or mulching as auxiliary measures. The application of straw can increase the concentration of SOC and promote the recycling of straw nutrients in the soil. The organic cement produced after straw decomposition can also promote the formation of soil aggregates, strengthen the cohesion between soil particles, and improve the structure of soil aggregates (BlancoCanqui and Lal, 2004; Abiven et al., 2009; Blanco-Moure et al., 2012). For example, $\mathrm{Gu}$ et al. (2014) studied the effect of corn straw treatment on aggregate composition and OC concentration of aggregates in brown soil, which showed that the addition of corn straw significantly increased the content of $>2000 \mu \mathrm{m}$ water-stable aggregates, reduced the content of $250-2000 \mu \mathrm{m}$ and $<250 \mu \mathrm{m}$ aggregates, and increased the stability of aggregates and OC concentration of aggregates. Tang et al. (2011) studied the effect of plant residue decomposition on the quantity and stability of red soil aggregates, which showed that straw treatment significantly promoted the formation of $>2000 \mu \mathrm{m}$ and 
250-2000 $\mu \mathrm{m}$ water-stable aggregates, and improved the stability of aggregates. According to the above studies, straw addition has a great influence on the distribution, stability and OC concentration of soil aggregates. Soil aggregation processes were very complicated, different types of soil contain different clay minerals, which will affect the agglomeration of aggregates and the retention of $\mathrm{OC}$, it is necessary to explore the agglomeration of aggregates and the retention of OC with the application of straw after the application of straw in different types of soil. However, there are few reports about the effect of straw decomposition on aggregates stability and aggregate-associated OC of different types of soil. It is difficult to distinguish the difference about straw decomposition on the distribution and stability of aggregates and aggregate associated OC of different types of soil, which requires further study. To this end, this paper studies the effect of straw application on the distribution and stability of water-stable aggregates in three different types of soil, and explores the distribution law of OC in different particle-size aggregates and the contribution rate of aggregate-associated OC during the process of rice straw decomposition with disturbance-free indoor incubation experiment. This study aims to provide theoretical support for the improvement of aggregate structure and $\mathrm{OC}$ in different types of soil.

\section{Materials and Methods}

\section{Site description and experimental samples}

The three typical soil samples were red soil (R Soil), fluvo-aquic soil (FA Soil) and lime concretion black soil (LCB Soil) in China, which were collected in their respective test stations in September 2014 with a sampling depth of 0-30 cm (Fig. 1). Five sampling points were evenly mixed and then quartered for sampling. Specifically, the sampling area of R soil is located in Yingtan R Soil Ecological Experimental Station of Chinese Academy of Sciences, Jiangxi Province, China $\left(116^{\circ} 55^{\prime} \mathrm{E}, 28^{\circ} 15^{\prime} \mathrm{N}\right)$. The soil type is R soil developed from Quaternary red clay and the parent rock mineral types are mainly iron-aluminum oxides and 1:1 clay mineral, which is classified as Ultisol in the USDA soil taxonomy; the sampling area of FA soil is located in Fengqiu Ecological Experimental Station, Henan Province, China $\left(114^{\circ} 24^{\prime} \mathrm{E}, 35^{\circ} 00^{\prime} \mathrm{N}\right)$. The soil type is FA soil developed from Yellow River sedimentation and the mineral type is mainly 2:1 clay mineral with high calcium carbonate content, which is classified as Inceptisol (USDA); the sampling area of the LCB soil (Vertisol) is located in Yangliu Experimental Site, Suixi, Anhui Province, China $\left(116^{\circ} 46^{\prime} \mathrm{E}, 33^{\circ} 37^{\prime} \mathrm{N}\right)$, and the mineral type is mainly $2: 1$ clay mineral with montmorillonite as the main component ( $\mathrm{Lv}$ and Li, 2006). After the coarse plant residues, large gravel and other impurities were removed from the collected soil, the soil was brought back to the laboratory for natural air drying in a cool and ventilated place, and then it was gently forced apart along the natural fragile zone so that it could pass through the $2 \mathrm{~mm}$ sieve. Special attention was paid to minimize the disturbance to the soil during the collection and transportation process to avoid the damage to the aggregates.

The basic properties of the three typical types of soil were shown in Table 1. The straw samples used in this experiment were rice straw cultivated in greenhouse. After 115 days of sowing, the above ground part of rice plants was obtained. After being dried at $60{ }^{\circ} \mathrm{C}$, the collected rice plant residues were crushed and put into bags after $0.25 \mathrm{~mm}$ sieving. The $\mathrm{C}$ and $\mathrm{N}$ concentration of rice straw was $396.5 \mathrm{~g} \mathrm{~kg}^{-1}$ and $16.5 \mathrm{~g} \mathrm{~kg}^{-1}, \mathrm{C} / \mathrm{N}$ ratio was 24.03 . 


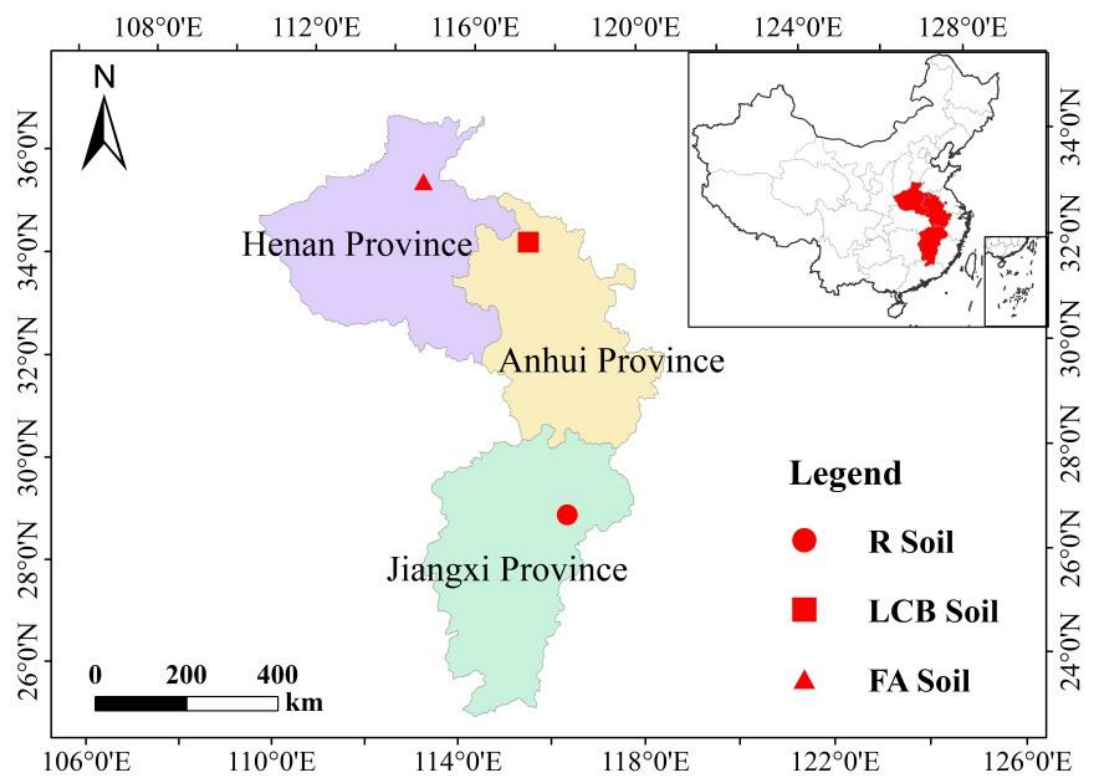

Figure 1. Location of the sampling site

Table 1. Properties of studied soil

\begin{tabular}{c|c|c|c|c|c|c|c}
\hline Soil Type & $\begin{array}{c}\text { Organic Carbon } \\
\mathbf{( g ~ k g}^{-1} \mathbf{)}\end{array}$ & $\begin{array}{c}\text { Total } \mathbf{~} \\
\mathbf{( g ~ k g}^{-1} \mathbf{)}\end{array}$ & $\mathbf{p H}$ & $\begin{array}{c}\text { Sand } \\
\mathbf{( \% )}\end{array}$ & $\begin{array}{c}\text { Silt } \\
(\mathbf{\%})\end{array}$ & $\begin{array}{c}\text { Clay } \\
(\mathbf{\%})\end{array}$ & $\begin{array}{c}\text { Texture } \\
(\mathbf{U S A D})\end{array}$ \\
\hline R Soil & $9.86 \pm 0.23$ & $1.12 \pm 0.01$ & $4.62 \pm 0.01$ & 36 & 20 & 44 & clay \\
FA Soil & $5.38 \pm 0.86$ & $0.57 \pm 0.05$ & $8.68 \pm 0.07$ & 23 & 32 & 45 & clay \\
LCB Soil & $10.45 \pm 0.33$ & $0.90 \pm 0.05$ & $6.34 \pm 0.02$ & 30 & 33 & 37 & clay loam \\
\hline
\end{tabular}

R Soil, red soil; LCB Soil, lime concretion black soil; FA Soil, fluvo-aquic soil

\section{Experimental design}

Self-designed experiment was conducted under three types of soil during different incubation periods. The experiment consisted of two treatments: no straw (control soil) and $1 \%$ straw (straw-amended soil). Each treatment was set with three repetitions. Specifically, three typical soil samples were sieved with a $2 \mathrm{~mm}$ sieve and $300 \mathrm{~g}$ were weighed into a $2 \mathrm{~L}$ plastic culture flask, $3 \mathrm{~g}$ of rice straw were added into the flasks, rice straw was evenly distributed in the test soil, then water was added to $70 \%$ of the maximum soil water capacity, and samples were incubated in a constant temperature incubator at $28^{\circ} \mathrm{C}$. Meanwhile, the control treatment was also prepared. During the whole incubation period, the daily ventilation was ensured and the weight was measured every week to keep the constant soil moisture content. Then three repeated treatments of soil were carried out after 15, 60 and 120 days of incubation to determine the aggregateassociated OC, water-stable aggregates and other indicators.

\section{Measurement indexes and methods}

The aggregate-associated $\mathrm{OC}$ was measured by potassium dichromate oxidationouter heating method; soil $\mathrm{pH}$ value was measured by potential method (soil water ratio 2.5:1); soil clay and silt content were measured by pipette method (Tiessen and Moir, 1993; Bao, 2000). Total carbon content of straw was measured by $\mathrm{C} / \mathrm{N}$ element analyzer; 
distribution and stability of soil aggregates were measured by wet sieving method, and water-stable aggregates with particle sizes of $>2,0.25-2,0.053-0.25$ and $<0.053 \mathrm{~mm}$ were obtained (Nimmo et al., 2002; Six et al., 2004). The detailed calculation equations of stability index $R_{0.25}$ ( $>0.25 \mathrm{~mm}$ water-stable macroaggregates), geometric mean diameter $(\mathrm{GMD})$, soil unstable aggregate exponent $\left(E_{L T}\right)$, mean weight diameter (MWD), fractal dimension $(D)$ and contribution rate of soil water-stable aggregate OC were extracted from relevant references and calculated as the following equations (Liu et al., 2012; An et al., 2016; Zhu et al., 2017; Xue et al., 2019).

$$
\begin{gathered}
\mathrm{MWD}=\frac{\sum_{i=1}^{n}\left(\overline{x_{l}} w_{i}\right)}{\sum_{i=1}^{n} w_{i}} \\
\mathrm{GMD}=\exp \left(\frac{\sum_{i=1}^{n} w_{i} \ln \bar{x}_{l}}{\sum_{i=1}^{n} w_{i}}\right) \\
E_{L T}=\frac{M_{T}-R_{0.25}}{M_{T}} \times 100 \% \\
\frac{M\left(r<\overline{x_{l}}\right)}{M_{\mathrm{T}}}=\left(\frac{\bar{x}_{l}}{x_{\max }}\right)^{3-D}
\end{gathered}
$$

where $\mathrm{n}$ denotes the number of aggregate size fractions, $\bar{x}_{l}$ is the mean diameter of aggregates retained in the $i$ th sieve, $W_{i}$ is the aggregate weight retained in the $i$ th sieve, $M\left(r \leq x_{i}\right)$ is the weight of aggregates with a fraction diameter less than or equal to $x_{i}$, and $M_{\mathrm{T}}$ is the gross weight of aggregates.

\section{Statistical analyses}

The data were organized via Microsoft Excel 2013, the mapping was made by SigmaPlot10.0, the one-way analysis of variance of experimental data was conducted through SPSS22.0 and the least significant range (LSD) method was used for multiple comparison, with $P<0.05$ indicating significance level.

\section{Results}

Effects of rice straw addition on the distribution of soil water-stable aggregates in different mineral types

The addition of rice straw in the three types of soil showed a significant effect on the dynamic changes of water-stable aggregates during the whole incubation period in the three different mineral soils (Fig. 2), the water-stable macroaggregates $(>0.25 \mathrm{~mm})$ significantly increased, and the water-stable microaggregates $(<0.25 \mathrm{~mm})$ significantly reduced $(P<0.05)$. The three types of control soil mainly contained water-stable microaggregates in the incubation process, and the proportion of $>2 \mathrm{~mm}$ aggregates was very little, which was significantly different $(P<0.05)$ from the other three particle-size aggregates; from day 15 to day 60 , the number of macroaggregates showed no significant difference of the control treatment, after 120 days of incubation, for the 
control soil, the proportion of water-stable macroaggregates increased slightly, but the water-stable microaggregates were still dominant.

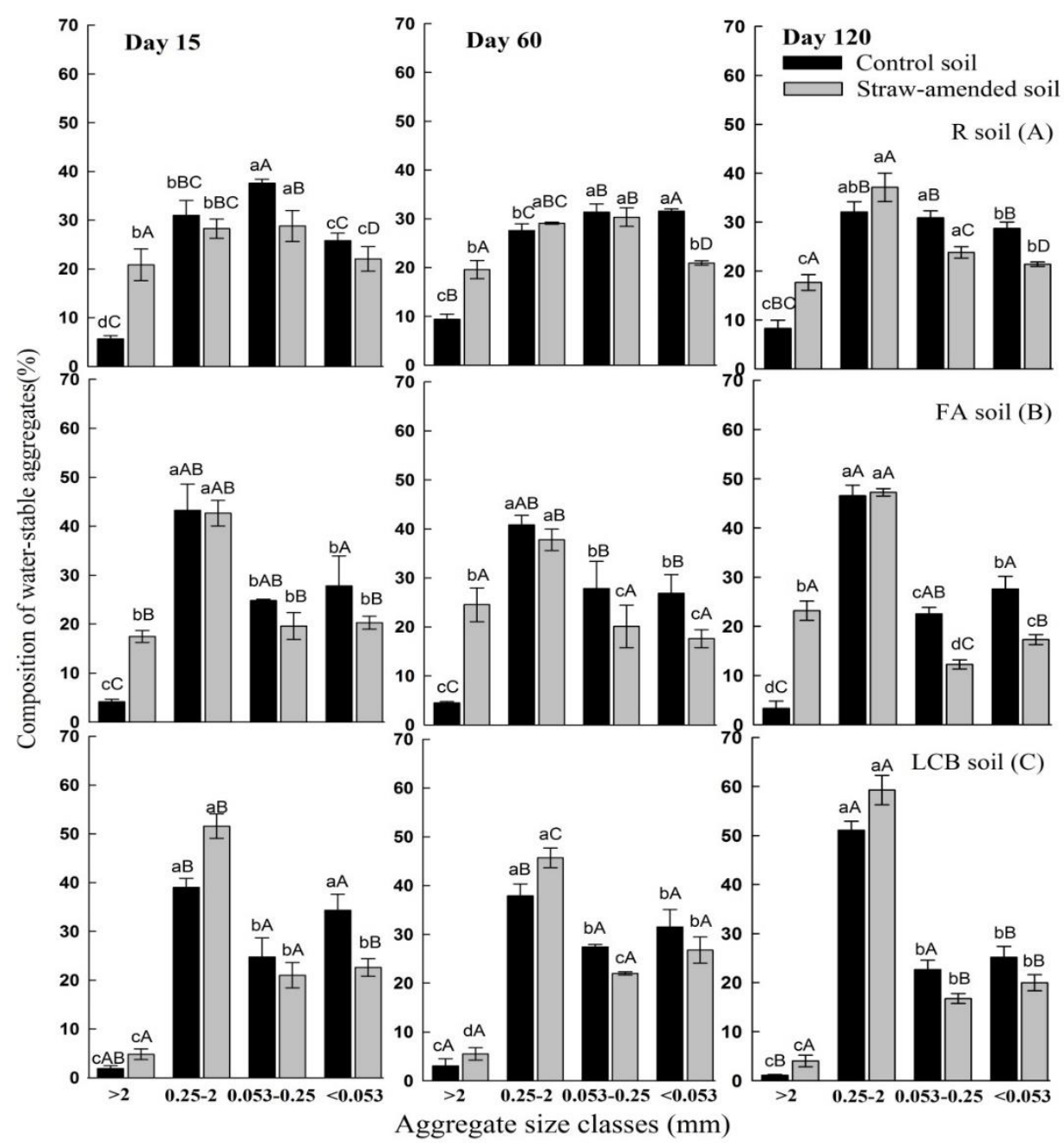

Figure 2. Water-stable aggregate size distribution under different incubation periods (\%). Different lowercase letters indicate significant differences among different particle-size aggregates under same treatments for the same incubation period $(P<0.05)$. Different uppercase letters indicate significant differences among the same particle-size aggregates in the same soil type under different treatments for different incubation periods $(P<0.05) . R_{0.25},>0.25$ $m m$ aggregates (water-stable macroaggregates). $R$ Soil, red soil; LCB Soil, lime concretion black soil; FA Soil, fluvo-aquic soil

Compared with the control soil, the three types of straw-amended soil showed a significant increase in $>2 \mathrm{~mm}$ water-stable macroaggregates and remarkable decrease in $0.053-0.25 \mathrm{~mm}$ and $<0.053 \mathrm{~mm}$ water-stable microaggregates during the early 15 days of incubation (Fig. 2). The proportion of macroaggregates $\left(R_{0.25}\right)$ was increased by 270.3, 108.3 and $113.5 \%$ for the R soil (Fig. 2A), 598.2, 449.6 and $321.3 \%$ for the FA soil (Fig. 2B), and 157.2, 79.5 and $265.5 \%$ for the LCB soil after 15, 60, and 120 days of incubation (Fig. 2C), respectively, from day 15 to day 120 the amounts of newly formed $>2 \mathrm{~mm}$ macroaggregates were significantly larger in the FA soil than in the R soil and in the LCB soil. With the increase of incubation time, the water-stable 
macroaggregates $\left(R_{0.25}\right)$ of $\mathrm{R}$ soil and LCB soil increased more rapidly during the early incubation stage (within 15 days) than during the later stage (from day 15 to day 60). Among them, the water-stable macroaggregates of FA soil showed a continuous increase, and that of R soil and LCB soil showed a trend of increase first, then a slight decrease and then an increase during the whole incubation period. After 120 days of incubation, $>2 \mathrm{~mm}$ water-stable aggregates in straw-amended R soil, LCB soil and FA soil were $113.5 \%, 298.0 \%$ and $595.8 \%$ higher than those in the control soil with the largest increase in FA soil. The 0.25-2 mm water-stable aggregates in straw-amended $\mathrm{R}$ soil, LCB soil and FA soil were $15.6 \%, 16.0 \%$ and $1.5 \%$ higher than that in the control soil with the largest increase in LCB soil. After 120 days of incubation, the order of water-stable macroaggregate in three types of soil was: FA soil $>$ LCB soil $>$ R soil, with a proportion of $70.4 \%, 63.3 \%$ and $54.8 \%$, respectively, and the water-stable macroaggregates accounted for the majority in all straw-amended soil. The water-stable macroaggregate in R soil, LCB soil and FA soil increased by $35.6 \%, 22.0 \%$ and $41.1 \%$, respectively after 120 days of incubation compared with the control soil, with the most obvious increase proportion in the FA soil.

\section{Effects of rice straw addition on $M W D, G M D, D$ and $E_{L T}$ of three different mineral soils}

Water-stable aggregate stability is an important indicator of soil structure, the addition of rice straw had a different positive effect on the stability of three types of soil aggregates during the incubation (Table 2). During the 120-days incubation period, MWD and GMD values of three types of straw-amended soils were significantly higher than those of the control soil, and $E_{L T}$ and $D$ values were significantly lower than those of the control soil $(P<0.05)$. However, from day 0 to day 120, the differences of MWD, GMD, $E_{L T}$ and $D$ values of all control soils in different incubation periods were not very obvious. With the extension of incubation period, the MWD, GMD, $E_{L T}$ and $D$ values of the straw-amended soil at day 120 showed better changing trend than at day 15 and day 60 , and the soil structural stability enjoyed continuous improvement. After 120 days of incubation, compared with the corresponding figures in the control treatment, the strawamended FA soil's MWD and GMD increased by $59.4 \%$ and $90.3 \%$, respectively, and its $D$ and $E_{L T}$ decreased by $8.1 \%$ and $40.7 \%$ respectively; the straw-amended R soil's MWD and GMD increased by $40.0 \%$ and $53.8 \%$ respectively, and its $D$ and $E_{L T}$ decreased by $3.8 \%$ and $24.2 \%$; and the straw-amended LCB soil's MWD and GMD increased by $21.9 \%$ and $36.4 \%$, respectively, and its $D$ and $E_{L T}$ decreased by $1.7 \%$ and $23.2 \%$. Apparently, the FA soil showed the most prominent change of aggregate stability compared with R soil and LCB soil.

\section{Effect of straw addition on the concentration of soil aggregate-associated organic carbon in different mineral types}

Compared with the control treatment, the OC concentration of different particle-size aggregates in different types of straw-amended soil increased significantly $(P<0.05)$, and the distribution of $\mathrm{OC}$ in different particle-size aggregates was significantly different (Fig. 3). During the whole incubation period, the OC concentration of the straw-amended soil aggregate was the highest after 15 days of incubation. During the later incubation stage (from day 15 to day 120), the OC concentration of the strawamended soil aggregates decreased gradually. In general, the increase of OC concentration in microaggregates of three types of straw-amended soil was larger than that in macroaggregates, and the concentration of $\mathrm{OC}$ in water-stable microaggregates 
was higher than that in macroaggregates. In addition, with the extension of incubation period, these were few changes in the aggregate-associated OC concentration of the control treatment. The analysis results from aggregate-associated OC indicated that straw application had main effect on the improvement of aggregate-associated OC in different mineral soils, while incubation time and soil type had little effect on aggregateassociated OC in general (Fig. 3).

Table 2. Effects of rice straw on aggregate stability index

\begin{tabular}{|c|c|c|c|c|c|c|}
\hline \multirow{2}{*}{$\begin{array}{l}\text { Soil } \\
\text { type }\end{array}$} & \multirow{2}{*}{$\begin{array}{c}\text { Time } \\
\text { (days) }\end{array}$} & \multirow{2}{*}{ Treatments } & \multicolumn{4}{|c|}{ Wet sieving } \\
\hline & & & MWD (mm) & GMD (mm) & $D$ & $E_{L T} / \%$ \\
\hline \multirow{6}{*}{ R Soil } & \multirow{2}{*}{15} & \multirow{6}{*}{$\begin{array}{l}\text { control soil } \\
\text { straw-amended soil } \\
\text { control soil } \\
\text { straw-amended soil } \\
\text { control soil } \\
\text { straw-amended soil }\end{array}$} & $0.53 \pm 0.02 b$ & $0.25 \pm 0.01 \mathrm{c}$ & $2.94 \pm 0.01 \mathrm{a}$ & $63.4 \pm 3.73 a$ \\
\hline & & & $0.79 \pm 0.06 \mathrm{a}$ & $0.36 \pm 0.04 \mathrm{~b}$ & $2.76 \pm 0.04 \mathrm{~b}$ & $50.9 \pm 5.23 b$ \\
\hline & \multirow{2}{*}{60} & & $0.56 \pm 0.02 b$ & $0.24 \pm 0.01 \mathrm{c}$ & $2.90 \pm 0.01 \mathrm{a}$ & $63.0 \pm 2.45 \mathrm{a}$ \\
\hline & & & $0.78 \pm 0.04 \mathrm{a}$ & $0.36 \pm 0.02 b$ & $2.77 \pm 0.02 b$ & $51.3 \pm 2.06 \mathrm{~b}$ \\
\hline & \multirow{2}{*}{120} & & $0.59 \pm 0.01 \mathrm{~b}$ & $0.26 \pm 0.01 \mathrm{c}$ & $2.91 \pm 0.02 \mathrm{a}$ & $59.6 \pm 3.72 \mathrm{a}$ \\
\hline & & & $0.82 \pm 0.01 \mathrm{a}$ & $0.40 \pm 0.01 \mathrm{a}$ & $2.80 \pm 0.02 \mathrm{~b}$ & $45.2 \pm 4.49 b$ \\
\hline \multirow{6}{*}{$\begin{array}{c}\text { LCB } \\
\text { Soil }\end{array}$} & \multirow{2}{*}{15} & control soil & $0.53 \pm 0.01 \mathrm{~d}$ & $0.24 \pm 0.01 \mathrm{~d}$ & $2.97 \pm 0.01 \mathrm{a}$ & $59.1 \pm 0.61 \mathrm{a}$ \\
\hline & & straw-amended soil & $0.72 \pm 0.01 \mathrm{~b}$ & $0.38 \pm 0.01 \mathrm{~b}$ & $2.91 \pm 0.02 b c$ & $43.6 \pm 1.77 \mathrm{bc}$ \\
\hline & \multirow{2}{*}{60} & control soil & $0.55 \pm 0.05 \mathrm{~d}$ & $0.25 \pm 0.03 \mathrm{~d}$ & $2.95 \pm 0.02 \mathrm{ab}$ & $59.0 \pm 3.24 \mathrm{a}$ \\
\hline & & straw-amended soil & $0.67 \pm 0.04 \mathrm{bc}$ & $0.33 \pm 0.03 \mathrm{c}$ & $2.90 \pm 0.02 \mathrm{c}$ & $48.8 \pm 2.99 \mathrm{~b}$ \\
\hline & \multirow{2}{*}{120} & control soil & $0.64 \pm 0.02 \mathrm{c}$ & $0.33 \pm 0.02 \mathrm{c}$ & $2.98 \pm 0.01 \mathrm{a}$ & $47.8 \pm 1.84 b$ \\
\hline & & straw-amended soil & $0.78 \pm 0.03 \mathrm{a}$ & $0.45 \pm 0.03 \mathrm{a}$ & $2.93 \pm 0.02 b c$ & $36.7 \pm 2.57 \mathrm{c}$ \\
\hline \multirow{6}{*}{ FA Soil } & \multirow{2}{*}{15} & control soil & $0.62 \pm 0.06 \mathrm{c}$ & $0.30 \pm 0.05 \mathrm{c}$ & $2.93 \pm 0.01 \mathrm{a}$ & $52.6 \pm 5.91 \mathrm{a}$ \\
\hline & & straw-amended soil & $0.87 \pm 0.05 b$ & $0.45 \pm 0.04 b$ & $2.67 \pm 0.02 b$ & $39.9 \pm 3.70 b$ \\
\hline & \multirow{2}{*}{60} & control soil & $0.60 \pm 0.02 \mathrm{c}$ & $0.29 \pm 0.01 \mathrm{c}$ & $2.92 \pm 0.01 \mathrm{a}$ & $54.7 \pm 2.26 \mathrm{a}$ \\
\hline & & straw-amended soil & $0.96 \pm 0.07 \mathrm{ab}$ & $0.51 \pm 0.06 b$ & $2.51 \pm 0.01 \mathrm{c}$ & $37.7 \pm 4.86 b$ \\
\hline & \multirow{2}{*}{120} & control soil & $0.63 \pm 0.04 \mathrm{c}$ & $0.32 \pm 0.03 \mathrm{c}$ & $2.95 \pm 0.03 \mathrm{a}$ & $50.2 \pm 2.07 \mathrm{a}$ \\
\hline & & straw-amended s & $1.03 \pm 0.03 \mathrm{a}$ & $0.59 \pm 0.02 \mathrm{a}$ & $2.55 \pm 0.04 \mathrm{c}$ & $29.7 \pm 1.87 \mathrm{c}$ \\
\hline
\end{tabular}

Different lowercase letters indicate significant differences among the same soil type under different treatments for different incubation periods $(P<0.05)$. R Soil, red soil; LCB Soil, lime concretion black soil; FA Soil, fluvo-aquic soil

For the transport and distribution of OC in aggregates, compared with the control soil, when the straw-amended soil was incubated for 15 days, the concentration of OC in the $>2,0.25-2,0.053-0.25$ and $<0.053 \mathrm{~mm}$ aggregates of FA soil increased by $42.7 \%$, $11.2 \%, 123.6 \%$ and $60.3 \%$, respectively (Fig. $3 A$ ); the concentration of organic carbon in the $>2,0.25-2,0.053-0.25$ and $<0.053 \mathrm{~mm}$ aggregates of $\mathrm{R}$ soil increased by $41.5 \%$, $8.1 \%, 21.5 \%$, and $11.5 \%$, respectively (Fig. $3 B$ ); the concentration of $\mathrm{OC}$ in the $>2$, $0.25-2,0.053-0.25$ and $<0.053 \mathrm{~mm}$ aggregates of LCB soil increased by $21.4 \%, 25.4 \%$, $34.7 \%$ and $50.0 \%$, respectively, the aggregate-associated OC in FA soil increased the most (Fig. 3C). From day 15 to day 120, the aggregate-associated OC of all types of straw-amended soil decreased gradually, the OC decomposition rate in macroaggregates was faster than that of microaggregates. In the incubation period of day 15 to day 120 , it was found that for the three types of soil, the increase of OC in water-stable microaggregates was larger than that in macroaggregates, and the differences of OC concentration between macroaggregates and microaggregate showed a decreasing trend. 
After 120 days of the incubation, except the $<0.053 \mathrm{~mm}$ aggregate in LCB soil, the OC of other aggregates fraction in three types of soil was still significantly $(P<0.05)$ higher than that in the control soil. The results showed that rice straw addition could improve the OC concentration of all aggregates in the three types of soil, and the increase of OC in microaggregates was significantly greater than that in the macroaggregates, but the increase degree of $\mathrm{OC}$ in aggregates of different types of soil was different during the 120 days of incubation period.

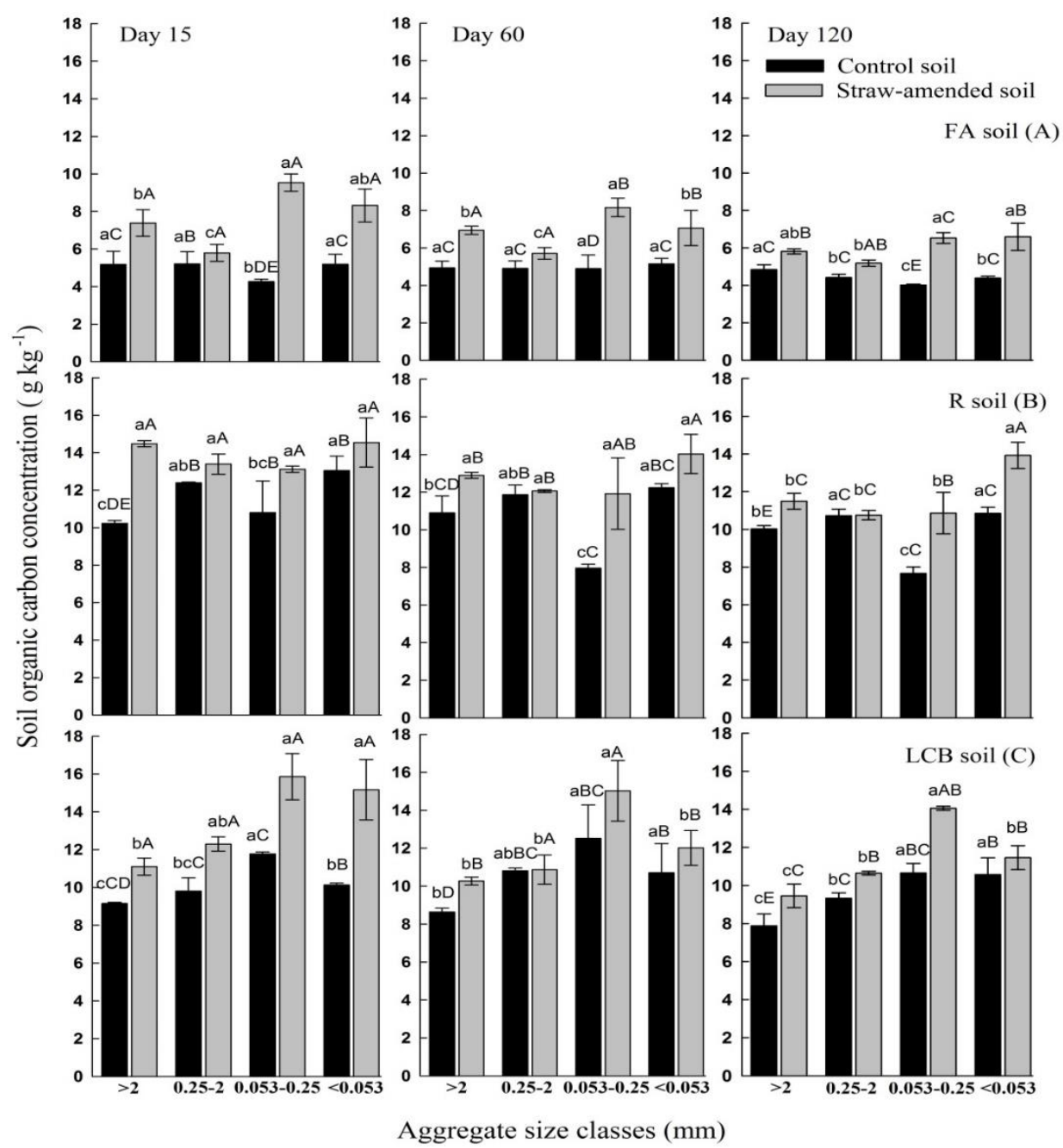

Figure 3. Concentration of aggregate-associated organic carbon in different types of soil during different incubation periods. Different lowercase letters indicate significant differences among different particle-size aggregates under the same treatment for the same incubation period $(P<0.05)$, and different uppercase letters indicate significant differences among the same particle-size aggregates in the same soil type under different treatments for different incubation period (P<0.05). R Soil, red soil; LCB Soil, lime concretion black soil; FA Soil, fluvo-aquic soil

\section{Contribution rate of organic carbon in different particle-size aggregates of three types of soil to the soil organic carbon}

Straw addition also had a great impact on the contribution rate of OC in different particle-size aggregates to the SOC (Table 3). For the control soil, there was slight 
change in the contribution rate of OC in different particle-size aggregates to the SOC, which was mainly reflected in the contribution rate of water-stable microaggregate OC to SOC. Compared with the control soil, after 15 days of incubation, the three strawamended soil types showed a significant increase in the contribution rate of $>2 \mathrm{~mm}$ water-stable macroaggregates and significant decrease $(P<0.05)$ in the contribution rate of $0.053-0.25 \mathrm{~mm}$ and $<0.053 \mathrm{~mm}$ water-stable microaggregates. After 120 days of incubation, the contribution rate of OC in $>2 \mathrm{~mm}$ aggregates of R soil, LCB soil and FA soil increased by $105.6 \%, 290.8 \%$ and $541.0 \%$, respectively; the contribution rate of OC in $>0.25 \mathrm{~mm}$ aggregates of R soil, LCB soil and FA soil increased by $18.6 \%, 20.7 \%$, and $29.4 \%$, respectively; and the contribution rate of water-stable macroaggregates in the three types of soil reached $51.98 \%, 59.07 \%, 66.14 \%$, respectively; the highest contribution rate of water-stable macroaggregates to the SOC was found in the FA soil and the lowest of that was found in the R soil.

Table 3. Contributing rates of water-stable aggregates carbon of different particle-size to soil organic carbon (\%)

\begin{tabular}{|c|c|c|c|c|c|c|}
\hline \multirow{2}{*}{$\begin{array}{l}\text { Soil } \\
\text { type }\end{array}$} & \multirow{2}{*}{$\begin{array}{c}\text { Time } \\
\text { (days) }\end{array}$} & \multirow{2}{*}{ Treatments } & \multicolumn{4}{|c|}{ Aggregate size } \\
\hline & & & m & $0.25-2 \mathrm{~mm}$ & $0.053-0.25 \mathrm{~mm}$ & $<0.053 \mathrm{~mm}$ \\
\hline \multirow{6}{*}{ R Soil } & \multirow{2}{*}{15} & \multirow{4}{*}{$\begin{array}{c}\text { control soil } \\
\text { straw-amended soi } \\
\text { control soil } \\
\text { straw-amended soil }\end{array}$} & $4.85 \pm 0.35 b D$ & $32.54 \pm 4.3$ & & $28.38 \pm 0$ \\
\hline & & & $21.84 \pm 2.48 \mathrm{bA}$ & $27.47 \pm 1.65 \mathrm{aC}$ & $27.48 \pm 3.48 \mathrm{aBC}$ & $23.2 \pm 2.3$ \\
\hline & \multirow{2}{*}{60} & & $9.61 \pm 1.31 \mathrm{dC}$ & $30.71 \pm 1.97 \mathrm{bAB}$ & $23.45 \pm 1.94 \mathrm{cAB}$ & $36.23 \pm 0.53 \mathrm{aA}$ \\
\hline & & & $20.07 \pm 1.02 \mathrm{cAB}$ & $27.94 \pm 0.76 \mathrm{aBC}$ & $28.56 \pm 2.01 \mathrm{aB}$ & $23.43 \pm 2.53 \mathrm{bD}$ \\
\hline & \multirow{2}{*}{120} & cont & $8.52 \pm 1.77 \mathrm{cC}$ & $35.32 \pm 3.17 \mathrm{aA}$ & $24.28 \pm 1.96 \mathrm{bBC}$ & $31.89 \pm 0.61 \mathrm{aB}$ \\
\hline & & straw-c & $17.52 \pm 0.89 \mathrm{~dB}$ & & $22.27 \pm 0.84 \mathrm{cC}$ & $25.75 \pm 0.95 \mathrm{bCD}$ \\
\hline \multirow{6}{*}{$\begin{array}{c}\text { LCB } \\
\text { Soil }\end{array}$} & \multirow{2}{*}{15} & & $1.63 \pm 0.21 \mathrm{cAB}$ & $36.82 \pm 2.63 \mathrm{aB}$ & $28.07 \pm 2.6$ & $33.46 \pm 2.93 \mathrm{abA}$ \\
\hline & & straw & 3.9 & $\mathrm{aA}$ & & 23.74 \\
\hline & \multirow{2}{*}{60} & con & $2.38 \pm 0.24 \mathrm{cA}$ & $36.76 \pm 2.69 \mathrm{aB}$ & $30.79 \pm 2.59 \mathrm{bA}$ & $30.06 \pm 3.27 \mathrm{bA}$ \\
\hline & & straw-a & & $41.27 \pm 3.05 \mathrm{aB}$ & $27.47 \pm 3.75 \mathrm{bA}$ & $26.58 \pm 2.27 \mathrm{bA}$ \\
\hline & \multirow{2}{*}{120} & con & $0.87 \pm 0.06 \mathrm{cB}$ & $48.05 \pm 2.56 \mathrm{aA}$ & $24.27 \pm 1.47 \mathrm{bB}$ & $26.82 \pm 1.94 \mathrm{bB}$ \\
\hline & & straw-a & $3.40 \pm 0.30 \mathrm{cA}$ & $55.67 \pm 3.36 \mathrm{aA}$ & $20.77 \pm 1.54 \mathrm{bA}$ & $20.16 \pm 1.66 \mathrm{bB}$ \\
\hline \multirow{6}{*}{ FA Soil } & \multirow{2}{*}{15} & & $4.27 \pm 0.04 \mathrm{cB}$ & $45.37 \pm 1.53 \mathrm{aA}$ & $21.40 \pm 1.18 \mathrm{bB}$ & $28.96 \pm 2.14 \mathrm{bA}$ \\
\hline & & straw-amended soil & $17.70 \pm 2.46 \mathrm{bA}$ & $33.80 \pm 2.73 \mathrm{aB}$ & $25.49 \pm 2.90 \mathrm{abA}$ & $23.02 \pm 1.39 \mathrm{abB}$ \\
\hline & \multirow{2}{*}{60} & control soil & $4.40 \pm 0.26 \mathrm{cB}$ & $40.19 \pm 4.93 \mathrm{aA}$ & $27.74 \pm 3.90 \mathrm{bA}$ & $27.68 \pm 2.51 \mathrm{bA}$ \\
\hline & & straw-amended soil & $25.42 \pm 4.96 \mathrm{bA}$ & $32.05 \pm 2.26 \mathrm{aB}$ & $24.11 \pm 3.18 \mathrm{bA}$ & $18.42 \pm 4.61 \mathrm{bB}$ \\
\hline & \multirow{2}{*}{120} & control soil & $3.66 \pm 0.42 \mathrm{~dB}$ & $47.47 \pm 2.41 \mathrm{aA}$ & $20.90 \pm 1.22 \mathrm{cA}$ & $27.97 \pm 2.89 \mathrm{bA}$ \\
\hline & & straw-amended soil & $23.46 \pm 1.98 \mathrm{bA}$ & $42.68 \pm 1.91 \mathrm{aB}$ & $13.92 \pm 0.80 \mathrm{cB}$ & $19.94 \pm 3.03 \mathrm{bB}$ \\
\hline
\end{tabular}

Different lowercase letters indicate significant differences among different particle-size aggregates under the same treatments for the same incubation period $(\mathrm{P}<0.05)$, and different uppercase letters indicate significant differences among the same particle-size aggregates in the same soil type under different treatments for different incubation periods $(\mathrm{P}<0.05)$

\section{Correlation between water-stable macroaggregates $\left(R_{0.25}\right)$ and mean weight diameter (MWD) in different mineral soils}

There was a significant positive correlation between the $>0.25 \mathrm{~mm}$ water-stable macroaggregates $\left(R_{0.25}\right)$ of the three types of soil and MWD (Fig. 4; R Soil, R ${ }^{2}=0.9446$, $P<0.0001$; FA Soil, $\mathrm{R}^{2}=0.9610, P<0.0001$; LCB Soil, $\left.\mathrm{R}^{2}=0.9758, P<0.0001\right)$, indicating 
that the more the $R_{0.25}$, the larger the MWD value of soil aggregates, and the greater water stability of soil aggregates and the more stable of the soil structure. In general, as the addition of rice straw to three different types of soil could increase the proportion of macroaggregate and its water stability, it was an effective way to improve the physical and chemical properties of soil and enhanced the erosion resistance, but the improvement degree of aggregate stability of different mineral soils was different.

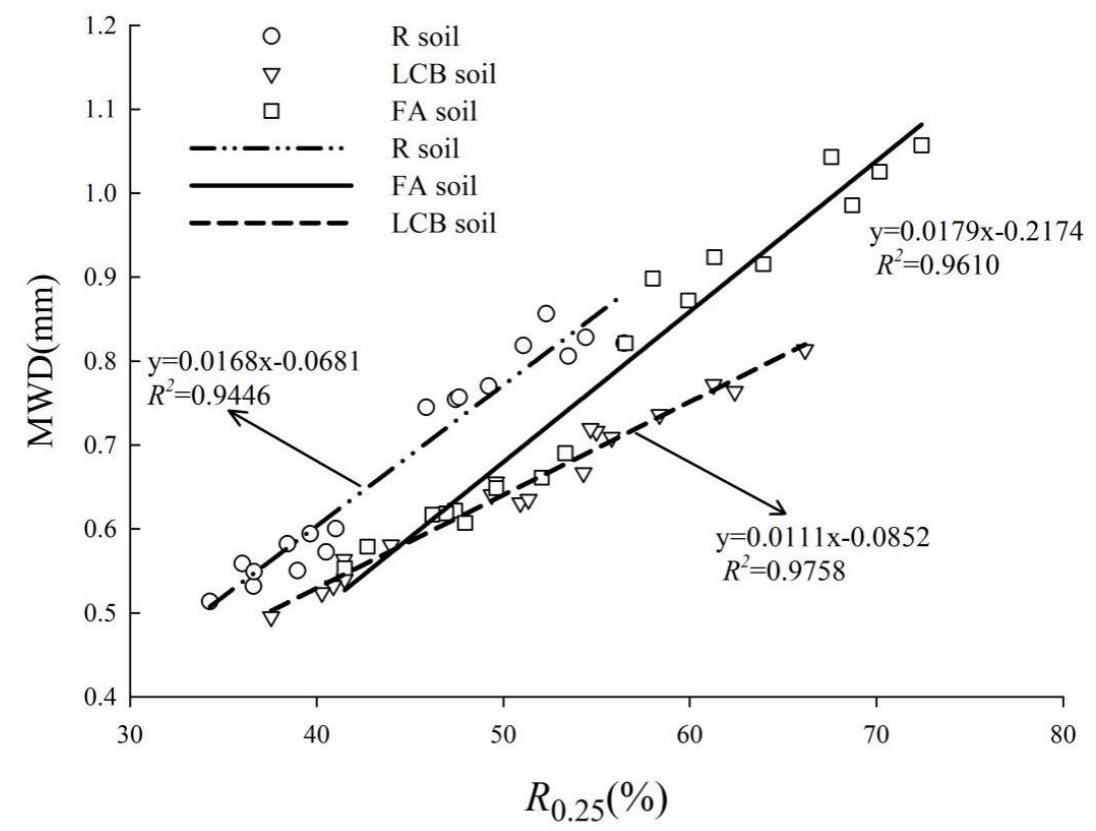

Figure 4. Correlation between the proportion of $>0.25 \mathrm{~mm}$ water-stable aggregates $\left(R_{0.25}\right)$ and mean weight diameter (MWD). R Soil, red soil; LCB Soil, lime concretion black soil; FA Soil, fluvo-aquic soil

\section{Discussions}

Effect of rice straw addition on distribution and stability of water-stable aggregates in different types of soil

The results of this study showed that rice straw addition had a significant impact on the distribution and stability of three different types of soil aggregates. For the three types of straw-amended soil, the proportion of $>2 \mathrm{~mm}$ and $0.25-2 \mathrm{~mm}$ water-stable macroaggregates increased significantly, and the proportion of $0.053-0.25 \mathrm{~mm}$ and $<0.053 \mathrm{~mm}$ water-stable microaggregates decreased significantly during the incubation period of day 15 day 60 and day 120 compared to the control treatment (Fig. 2) $(P<0.05)$. As a new exogenous carbon source, rice straw could increase the input of soil organic materials. The research showed that the increase of exogenous organic materials improved the activity of microorganisms and enzymes, and promoted the growth of microbial hyphae. With the growth of fungal mycelium and the decomposition of other microorganisms, the organic materials would be transformed to humus which was an important cement for the formation of aggregates. The humus can promote the combination of soil particles and minerals, with a stimulating effect on the formation of aggregates to promote microaggregates to be formed into macroaggregates (Verchot et al., 2011; Cui et al., 2011). The results of the experiment were similar to those of Sodhi 
et al. (2009), who found that rice straw compost could significantly increase the proportion of $>0.25 \mathrm{~mm}$ water- stability macroaggregates in sandy loam. However, straw addition had different distribution and migration of three types of soil aggregates at different particle sizes, the amounts of newly formed $>2 \mathrm{~mm}$ macroaggregates were significantly larger at the early incubation stage (within 15 days) than later incubation stage (from day 60 to day 120). After 120 days of incubation, the $>2 \mathrm{~mm}$ water-stable aggregates in straw-amended R soil, LCB soil and FA soil were $113.5 \%, 298.0 \%$ and $595.8 \%$ higher than those in the control soil with the largest increase in FA soil and their concentrations were $17.68 \%, 4.02 \%$ and $23.18 \%$, respectively. The order of the proportion of water-stable macroaggregate in the three types of soil was FA soil > LCB soil > R soil, and the increasing proportion of water-stable macroaggregate in FA soil was the most obvious from day 15 to day 120 (Fig. 2). On the one hand, the reason may be that the added rice straw was more finely crushed, and the finer the straw was, the easier it was to be used by microorganisms, and the closer it would be combined with the soil. After the straw was decomposed, it could provide rich carbon source for the microorganisms in the soil, stimulate the microbial activity, and lead to the increase of water-stable macroaggregates. On the other hand, the FA soil and LCB soil were 2:1type clay minerals mainly composed of montmorillonite with high constant surface charge and large specific surface, but $\mathrm{R}$ soil was a highly weathered soil mainly composed of iron aluminum oxide and 1:1 clay mineral with large crystal particles and relatively small specific surface. ANOVA results of control soils from Figure 2 showed that incubation time and soil types were not the major factors on the formation of aggregates, while according to ANOVA results of straw-amended soils, straw application was considered as the main effect on the formation of aggregates compared with control soils. According to the multilevel aggregate formation theory, 2:1 clay minerals (FA soil and LCB soil) had stronger adsorption capacity for organic matter than 1:1 clay minerals ( $\mathrm{R}$ soil), and the organic binding agents play dominant roles in the formation and stabilization of soil aggregates with 2:1 clay minerals. Compared with $\mathrm{R}$ soil, FA soil and LCB soil would be more conducive to the formation of water-stable macroaggregates (Tisdall and Oades, 1982; Lugato et al., 2010).

MWD, GMD, $D$ and $E_{L T}$ of soil aggregates can better reflect the size distribution transformation, aggregation and erosion resistance of soil aggregates. The larger MWD and GMD values as well as the smaller $D$ and $E_{L T}$ values that indicate the higher average aggregation, the better structure and stability of the soil, and the stronger erosion resistance (Stoops, 2003; Wang et al., 2013; Tang et al., 2016). Compared with the control soil, the MWD and GMD values of water-stable aggregates in three types of straw-amended soil increased significantly and the $D$ and $E_{L T}$ values in them decreased significantly. The differences of MWD, GMD, $E_{L T}$ and $D$ values of three types of soil in different incubation periods (from day 0 to day 120) were not always significantly in the control soil, but the MWD, GMD, $E_{L T}$ and $D$ values of straw-amended soil showed continuous improvement during the 120 days of incubation period, and the change of aggregate stability of FA soil was the most obvious at 120-day compared with LCB soil and $\mathrm{R}$ soil (Table 2). There was a significant positive correlation between $R_{0.25}$ and MWD in three mineral soils, which indicated that as $R_{0.25}$ increased due to straw application, the MWD values also increased. Straw is an important resource of SOC, which promotes the aggregation and water stability of aggregates. The difference of determination coefficient in correlation analysis showed that the improvement effect on LCB soil and FA soil, which were mainly composed of 2:1 clay mineral, was better (Fig. 
4). These results showed that with the addition of rice straw and the extension of incubation time, which improved the activity of microorganisms and enzymes, soil microorganisms can transform plant residues into organic binding agents, promoted the agglomeration of soil aggregates, and the degree of aggregation and stability of the three types of soil were significantly enhanced, and the soil structure was improved. Among them, the change of the stability of the FA soil was significant, which was consistent with the change of the macroaggregates, and the FA soil also enjoyed the best improvement of aggregate structural stability because FA soil was dominated by 2:1 clay mineral with high calcium carbonate contents, the content of silt and clay particles was greater than $77 \%$, and the organic binding agents play dominant roles in the stabilization of soil aggregates. This was similar to the research results of $\mathrm{Lu}$ et al. (2014) and Sodhi et al. (2009). Sodhi et al. (2009), which concluded that straw composting treatment could significantly improve MWD and soil structural stability of sandy loam; Lu et al. (2014) found that rice husk biochar treatment could not only significantly improve the proportion of $2-5 \mathrm{~mm}$ and $0.25-0.5 \mathrm{~mm}$ macroaggregates of modified clay, but also reduce the proportion of $<0.25 \mathrm{~mm}$ microaggregates, significantly improving MWD and GMD.

\section{Effect of rice straw addition on distribution and contribution rate of organic carbon in different particle-size aggregates}

The content of water-stable aggregates is an important indication to evaluate the stability of soil structure and erosion resistance, and relevant experimental studies had also revealed that the distribution of $\mathrm{OC}$ in different particle-size aggregates was different and the stability of OC in different particle-size aggregates was also different. The possible reason lies in that the distribution of exogenous new carbon in aggregates is different due to factors such as incubation conditions, soil types and types of exogenous materials (Tripathi et al., 2014; Zhang et al., 2016). The results of this study showed that the OC concentration of three types of straw-amended soil in four different particle-size aggregates was significantly $(P<0.05)$ higher than that of the control soil during the 120 days of incubation periods, and there was a certain difference in the OC concentration of different particle-size aggregates (Fig. 3). For the transport and distribution of aggregate-associated OC, compared with the control soil, when the straw-amended soil was incubated for 120 days, the concentration of OC in the $>2$, $0.25-2,0.053-0.25$ and $<0.053 \mathrm{~mm}$ aggregates of FA soil increased by $20.0 \%, 17.4 \%$, $62.6 \%$ and $50.4 \%$, respectively; the concentration of $\mathrm{OC}$ in the $>2,0.25-2,0.053-0.25$ and $<0.053 \mathrm{~mm}$ aggregates of $\mathrm{R}$ soil increased by $14.7 \%, 0.2 \%, 41.9 \%$, and $28.4 \%$, respectively; the concentration of $\mathrm{OC}$ in the $>2,0.25-2,0.053-0.25$ and $<0.053 \mathrm{~mm}$ aggregates of LCB soil increased by $19.9 \%, 14.1 \%, 32.0 \%$ and $8.4 \%$, respectively (Fig. $3)$. The results showed that the lower the initial organic carbon concentration of soil aggregates was, the larger the increase range of the aggregate-associated OC was, the OC concentration increased rapidly during the early incubation stage (within 15 days) in all three amended soils, especially, the FA soil increased the most, and the OC concentration of the straw-amended soil aggregates decreased gradually from day 15 to day 120.

The increase range of the OC concentration of water-stable microaggregate was significantly larger than that of the macroaggregate, and the increase range of aggregate-associated OC in FA soil was the largest from day 15 to day 120, and the OC concentration in the water-stable microaggregates of the three types of soil was 
generally higher than that of in the macroaggregates. This was similar to the results of Lee's study. Lee et al. (2009) studied the effect of different fertilization treatments on SOC and found that straw composting significantly increased the OC concentration of aggregates, and the $\mathrm{OC}$ concentration of water-stable microaggregates was higher than that of water-stable macroaggregates. The reason may be that the mineral types and clay content of the three types of soil were different, 2:1 clay minerals had stronger adsorption capacity for organic matter than 1:1 clay minerals. Due to the influence of biological, chemical and environmental factors, with the extension of incubation period, the aggregate-associated OC was gradually decomposing, OC available for microorganisms will decrease, and the straw crushing was relatively fine, which would have different effects on the increase and sequestration of OC of different particle-size aggregates. Moreover, the carbon sequestration by the microaggregates was not easy to decompose as it was protected physically and had biochemical resistance. Therefore, the OC of the microaggregates was more durable and stable in the soil. The FA soil and LCB soil contained higher silt and clay particles content with high constant surface charge and large specific surface, which would contribute to the increase and sequestration of the $\mathrm{OC}$ in the water-stable microaggregate. Therefore, the straw addition was of great significance to improve the soil structure and stability, increase OC concentration of soil aggregates, and improve carbon sequestration capacity (Six et al., 2000; Dimoyiannis, 2012; Song et al., 2019).

Compared with the control soil, after 15 days of incubation, all straw-amended soil types showed a significant increase in the contribution rate of water-stable macroaggregates and remarkable decrease $(P<0.05)$ in the contribution rate of water-stable microaggregates. After 120 days of incubation, the contribution rate of OC in water-stable macroaggregates of R soil, LCB soil and FA soil was $51.98 \%, 59.07 \%$, $66.14 \%$, respectively. The FA soil enjoyed the largest contribution rate of OC in water-stable macroaggregates to SOC (Table 3). The reason for the decrease of the contribution rate of $\mathrm{OC}$ in water-stable microaggregates may be that the addition of rice straw promoted the activity of microorganisms and enzymes, increased the organic cementing substance, and helped the water-stable microaggregates to continuously bond and aggregate into water-stable macroaggregates, and the distribution proportion of $>2 \mathrm{~mm}$ and $0.25-2 \mathrm{~mm}$ water-stable macroaggregates increased significantly. The increase extent of water-stable macroaggregates was larger than that of OC concentration in water-stable microaggregates, and the distribution proportion of waterstable microaggregates in the whole aggregates was relatively low.

\section{Conclusions}

Rice straw application resulted in significant effect on water-stable aggregates and aggregate-associated OC of the three typical types of soil during the whole incubation stage, which promoted the aggregation of water-stable microaggregates to macroaggregates. After 120 days of incubation, the proportion of water-stable macroaggregates in R soil, LCB soil and FA soil reached $54.8 \%, 63.3 \%$ and $70.4 \%$, respectively, becoming the dominant aggregates, significantly improving the MWD and GMD of soil water-stable aggregates, and reducing the $D$ and $E_{L T}$ values $(P<0.05)$. Furthermore, MWD and $R_{0.25}$ showed a significant positive correlation $(P<0.001)$. These results suggest that the addition of straw enhanced the degree of aggregation of water-stable aggregates and improved soil aggregate stability, the increase degree of 
aggregates content and stability was different, probably due to stronger adsorption capacity and high constant surface charge in $2: 1$ clay minerals than 1:1 clay minerals.

The straw addition also increased $O C$ concentration in different particle-size aggregates of three types of amended soil, and the OC concentration increased rapidly during the early 15 days of incubation in the three amended soils, the contribution rate of organic carbon in $>2 \mathrm{~mm}$ water-stable macroaggregates also significantly improved. Meanwhile, the increase of OC in water-stable microaggregates was larger than that in macroaggregates in all straw-amended soil. In conclusion, the addition of rice straw to three different types of soil was an effective way to increase the aggregates stability and aggregate-associated OC concentration, and the increase degree of aggregates stability and OC concentration of different types of soil was different, which could play a more important role in FA soil than in R soil and LCB soil.

This study analyzed the effects of straw addition on the distribution and stability of water-stable aggregates and aggregate associated $\mathrm{OC}$ in three different soil clay mineral types. Microbial processes related to decomposition of plant debris or root growth can greatly promote the formation of soil aggregates and nutrient decomposition. Therefore, the influence of straw addition on soil microbial biomass and microbial activity at different incubation stage should be further studied, and main factors affecting soil aggregates formation are also needed to be noticed. Additionally, the effect of straw addition on soil interparticle forces (electrostatic repulsive force, van der Waals attractive force and surface-hydration repulsive force) in different mineral types should be considered because they can reveal the relationship between the interparticle forces and soil structural stability. These further studies help to provide theoretical support for soil quality improvement in different mineral types.

Acknowledgments. This research was supported by the Scientific Research Item of Shaanxi Provincial Land Engineering Construction Group(DJNY2020-25), the 2018 Open Fund for Shaanxi Key Laboratory of Land Remediation(2018-JC15), and the Fundamental Research Funds for the Central University of Changan University (300102279502).

\section{REFERENCES}

[1] Abiven, S., Menasseri, S., Angers, D. A., Hans-Jörg, V. (2007): Dynamics of aggregate stability and biological binding agents during decomposition of organic materials. European Journal of Soil Science 58: 239-247.

[2] Abiven, S., Menasseri, S., Chenu, C. (2009): The effects of organic inputs over time on soil aggregate stability-A literature analysis. - Soil Biology \& Biochemistry 41: 1-12.

[3] An, Y., Ji, Q., Zhao, S. X., Wang, X. D. (2016): Effect of Biochar Application on Soil Aggregates Distribution and Moisture retention in Orchard Soil. - Environmental Science \& Technology 37: 293-300.

[4] Bandyopadhyay, K. K., Lal, R. (2014): Effect of land use management on greenhouse gas emissions from water stable aggregates. - Geoderma 232: 363-372.

[5] Bao, S. D. (2000): Soil and Agriculture Chemistry Analysis, $3^{\text {rd }}$ edition. - China Agricultural Press, Beijing.

[6] Bimüller, C., Kreyling, O., Kölbl, A., Lützow, M., Kögel-Knabner, I. (2016): Carbon and nitrogen mineralization in hierarchically structured aggregates of different size. - Soil \& Tillage Research 160: 23-33.

[7] Blanco-Canqui, H., Lal, R. (2004): Mechanisms of carbon sequestration in soil aggregates. - Critical Reviews in Plant Sciences 23: 481-504. 
[8] Blanco-Moure, N., Moret-Fernández, D., López, M. V. (2012): Dynamics of aggregate destabilization by water in soils under long-term conservation tillage in semiarid Spain. Catena 99: 34-41.

[9] Blaud, A., Lerch, T. Z., Chevallier, T., Nunan, N., Chenu, C., Brauman, A. (2012): Dynamics of bacterial communities in relation to soil aggregate formation during the decomposition of 13C-labelled rice straw. - Applied Soil Ecology 53: 1-9.

[10] Chivenge, P., Vanlauwe, B., Gentile, R., Six, J. (2011): Organic resource quality influences short-term aggregate dynamics and soil organic carbon and nitrogen accumulation. - Soil Biology \& Biochemistry 43: 657-666.

[11] Cui, R., Li, R., Han, Q., Jia, Z., Liang, L., Wang, X., Ma, X. (2011): Effects of different organic manure with fertilization on soil aggregates in dry farmland. - Journal of Northwest A \& F University 39: 124-132.

[12] Dimoyiannis, D. (2012): Wet aggregate stability as affected by excess carbonate and other soil properties. - Land Degradation \& Development 23: 450-455.

[13] Fonte, S. J., Yeboah, E., Ofori, P., Quansah, G. W., Vanlauwe, B., Six, J. (2009): Fertilizer and residue quality effects on organic matter stabilization in soil aggregates. Soil Science Society of America Journal 73: 961-966.

[14] Gu, X., An, T. T., Li, S. Y., Li, H., Wang, J. K. (2014): Effects of application of straw on organic carbon in brown soil aggregates by $\delta^{13} \mathrm{c}$ method. - Journal of Soil and Water Conservation 28: 243-247, 312 .

[15] Haydu-Houdeshell, C. A., Graham, R. C., Hendrix, P. F., Peterson, A. C. (2018): Soil aggregate stability under chaparral species in southern California. - Geoderma 310: 201208.

[16] Ji, B. Y., Hu, H., Zhao, Y. L., Mu, X. Y., Liu, K., Li, C. H. (2014): Effects of deep tillage and straw returning on soil microorganism and enzyme activities. - Scientific World Journal 2014: 451493.

[17] Lal, R. (2008): Soils and sustainable agriculture. A review. - Agronomy for Sustainable Development 28: 57-64.

[18] Lee, S. B., Lee, C. H., Jung, K. Y., Park, K. D., Lee, D., Kim, P. J. (2009): Changes of soil organic carbon and its fractions in relation to soil physical properties in a long-term fertilized paddy. - Soil \& Tillage Research 104: 227-232.

[19] Li, S., Li, Y., Huang, X., Hu, F., Liu, X., Li, H. (2017): Phosphate fertilizer enhancing soil erosion: effects and mechanisms in a variably charged soil. - Journal of Soils and Sediments 18: 1-11.

[20] Liu, X. H., Han, F. P., Zhang, X. C. (2012): Effect of Biochar on Soil Aggregates in the Loess Plateau: Results from Incubation Experiments. - International Journal of Agriculture and Biology 14: 975-979.

[21] Lu, N., Liski, J., Chang, R. Y., Akujärvi, A., Wu, X., Jin, T. T., Wang, Y. F., Fu, B. J. (2013): Soil organic carbon dynamics following afforestation in the Loess Plateau of China. - Biogeosciences 10: 7053-7063.

[22] Lu, S. G., Sun, F. F., Zong, Y. T. (2014): Effect of rice husk biochar and coal fly ash on some physical properties of expansive clayey soil (vertisol). - Catena 114: 37-44.

[23] Lugato, E., Simonetti, G., Morari, F., Nardi, S., Berti, A., Giardini, L. (2010): Distribution of organic and humic carbon in wet-sieved aggregates of different soils under long-term fertilization experiment. - Geoderma 157: 80-85.

[24] Lv, Y. Z., Li, B. G. (2006): Pedology. - China Agricultural Press, Beijing.

[25] Nimmo, J. R., Perkins, K. S. (2002): Aggregates Stability and Size Distribution. - In: Methods of Soil Analysis, Part4-Physical Methods. Soil Science Society of America Journal, Inc. Madison, Wisconsin, USA, pp. 317-328.

[26] Peth, S., Horn, R., Beckmann, F., Donath, T., Fischer, J., Smucker, A. J. M. (2008): Three-dimensional quantification of intra-aggregate pore-space features using synchrotron- radiation-based microtomography. - Soil Science Society of America Journal 72: 897-907. 
[27] Rabot, E., Wiesmeier, M., Schlüter, S., Vogel, H. J. (2018): Soil structure as an indicator of soil functions: a review. - Geoderma 314: 122-137.

[28] Six, J., Elliott, E. T., Paustian, K. (2000): Soil macroaggregate turnover and microaggregate formation: A mechanism for $\mathrm{C}$ sequestration under notillage agriculture. - Soil Biology \& Biochemistry 32: 2099-2103.

[29] Six, J., Bossuyt, H., Degryze, S., Denef, K. A. (2004): History of research on the link between (micro)aggregates, soil biota, and soil organic matter dynamics. - Soil \& Tillage Research 79: 7-31.

[30] Sodhi, G. P. S., Beri, V., Benbi, D. K. (2009): Soil aggregation and distribution of carbon and nitrogen in different fractions under long-term application of compost in rice-wheat system. - Soil \& Tillage Research 103: 412-418.

[31] Song, K., Zheng, X., Lv, W., Qin, Q., Sun, L., Zhang, H., Xue, Y. (2019): Effects of tillage and straw return on water-stable aggregates, carbon stabilization and crop yield in an estuarine alluvial soil. - Scientific Reports 9: 4586.

[32] Stoops, G. (2003): Guidelines for Analysis and Description of Soil and Regolith Thin Sections. - Soil Science Society of America Journal 19: 507-509.

[33] Tang, J., Mo, Y., Zhang, J., Zhang, R. (2011): Influence of biological aggregating agents associated with microbial population on soil aggregate stability. - Applied Soil Ecology 47: 153-159.

[34] Tang, F. K., Cui, M., Lu, Q., Liu, Y. G., Zhou, J. X. (2016): Effects of vegetation restoration on the aggregate stability and distribution of aggregate-associated organic carbon in a typical karst gorge region. - Solid Earth 7: 2213-2242.

[35] Tiessen, H., Moir, J. O. (1993): Total and Organic Carbon. - In: Carter, M. R. (ed.) Soil Sampling and Methods of Analysis. Journal of Environmental Quality 38: 187-199.

[36] Tisdall, J. M., Oades, J. M. (1982): Organic matter and water-stable aggregates in soils. European Journal of Soil Science 33: 141-163.

[37] Tripathi, R., Nayak, A. K., Bhattacharyya, P., Shukla, A. K., Shahid, M., Raja, R., Panda, B. B., Mohanty, S., Kumar, A., Thilagam, V. K. (2014): Soil aggregation and distribution of carbon and nitrogen in different fractions after 41-years long-term fertilizer experiment in tropical rice-rice system. - Geoderma 213: 280-286.

[38] Vaezi, A. R., Ahmadi, M., Cerdà, A. (2017): Contribution of raindrop impact to the change of soil physical properties and water erosion under semi-arid rainfalls. - Science of the Total Environment 583: 382-392.

[39] Vanhala, P., Karhu, K., Tuomi, M., Björklöf, K., Fritze, H., Liski, J. (2008): Temperature sensitivity of soil organic matter decomposition in southern and northern areas of the boreal forest zone. - Soil Biology \& Biochemistry 40: 1758-1764.

[40] Verchot, L. V., Dutaur, L., Shepherd, K. D., Albrecht, A. (2011): Organic matter stabilization in soil aggregates: understanding the biogeochemical mechanisms that determine the fate of carbon inputs in soils. - Geoderma 161: 182-193.

[41] Wang, F., Tong, Y. A., Zhang, J. S., Gao, P. C., Coffie, J. N. (2013): Effects of various organic materials on soil aggregate stability and soil microbiological properties on the Loess Plateau of China. Plant. - Plant Soil \& Environment 59: 162-168.

[42] Wang, D., Fonte, S. J., Parikh, S. J., Six, J., Scow, K. M. (2017): Biochar additions can enhance soil structure and the physical stabilization of c in aggregates. - Geoderma 303: $110-117$.

[43] Xue, B., Huang, L., Huang, Y., Yin, Z., Li, X., Lu, J. (2019): Effects of organic carbon and iron oxides on soil aggregate stability under different tillage systems in a rice-rape cropping system. - Catena 177: 1-12.

[44] Zhang, P., Wei, T., Jia, Z. K., Han, Q. F., Ren, X. L. (2014): Soil aggregate and crop yield changes with different rates of straw incorporation in semiarid areas of northwest China. - Geoderma 230: 41-49. 
[45] Zhang, J. G., Bo, G. D., Zhang, Z. F., Kong, F. Y., Wang, Y., Shen, G. M. (2016): Effects of Straw Incorporation on Soil Nutrients, Enzymes, and Aggregate Stability in Tobacco Fields of China. - Sustainability 8(8): 710.

[46] Zhu, G., Shangguan, Z., Deng, L. (2017): Soil aggregate stability and aggregateassociated carbon and nitrogen in natural restoration grassland and Chinese red pine plantation on the Loess Plateau. - Catena 149: 253-260. 